\title{
Design and analysis microstrip antenna with reflector to enhancement gain for wireless communication
}

\author{
Ali Khalid Jassim', Raad H. Thaher ${ }^{2}$ \\ ${ }^{1}$ Electrical Engineering Department, Al Mustansiriyh University, College of Engineering Baghdad, Iraq \\ ${ }^{2}$ College of Engineering-Al-Mustansiriyah University, Iraq
}

\section{Article Info \\ Article history: \\ Received Jul 30, 2019 \\ Revised Sep 26, 2019 \\ Accepted Jan 24, 2020}

\section{Keywords:}

Gain

Microstrip antenna

Reflector

Wavelength physical plane

\begin{abstract}
In this paper is presented the good solution to enhancement gain by using physical plane plate reflector with optimum distance by a reflector was used with the antenna and using a sweep parameter for the distance at which the reflector was placed at $(4,8,12,16) \mathrm{mm}$, we found the best distance is $\lambda$ when selected the bandwidth is $28 \mathrm{GHz}$ where $\lambda=12 \mathrm{~mm}$. The gain at the bandwidth in $28 \mathrm{GHz}$ was improved from $(5.48,6.78$, and 7.83$) \mathrm{dB}$ to $11.53 \mathrm{~dB}$, while the gain without a reflector is $7.1 \mathrm{~dB}$. The simulation results were obtained using CST which was more consistent with the practical results.
\end{abstract}

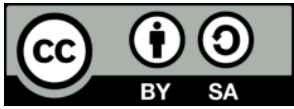

Corresponding Author:

Ali Khalid Jassim,

Electrical Engineering Department,

Al Mustansiriyh University, Baghdad, Iraq.

Email: alijassim79@yahoo.com

\section{INTRODUCTION}

The principle of reflector antenna in reality for the first time in 1963 demonstrated by Berry et al [1]. The length of the guided guide is adjusted independently by calibrating the reflected vector. After that, specifically in 1977, Phelan devised a new technique is to attach a switching diode with each arm of the four arms of the spiral antennas [2]. Using this idea, the radiated beam in the broadside direction gained a wide scanning angle [3]. After nearly 20 years, microstrip patch with an extension called phase delay component is utilized in reflectarray designing. Due to this extension, it absolutely was attainable to provide wider phase range for the reflected wave by changing the length of this extra component [4]. In order to obtain the best gain for the antenna, the best solution is to use the reflector for the radiator towards the source of the feed for easy implementation and lightweight. The actual level type in the reflector may be used for the ease of analysis and accuracy of performance required and most antennas used in the spacecraft use this type of reflector for the wave [5]. This technique has many other techniques for the design and implementation of the antenna system and the CST program has been used to design the antenna with the reflector for the wave.

\section{DESIGN METHODS OVERVIEW}

Direct optimization and phase-only synthesis, are the well-known methods for the design of the reflector. Direct optimization method (DOM), generally used for design reflector which consists of irregular-model elements that placed and oriented randomly. Whereas the elements of most kinds 
of the reflector are arranged in uniform-lattice, therefore, using this method as mentioned in [6], will be a waste of time and resources. Analyze and then improve all cases of the arrangement of the constituent elements of the reflector is done through the use of sophisticated software will take a long time and also needs tremendous computational capabilities, both of which are considered one of the resources that may not be allowed to be dissipated. The second method is known as, phase-only optimization method (POM), which is the best suited in designing the reflector that consists of elements arranged in a square grid and have a regular (or irregular) periodical pattern. This method functions effectively in regards to the time required to simulate and analyze the reflectarray structure as compared to the first method. POM is widely used in reflectarray designing; these are some researches that accomplished using this method [7-10]. POM consists of two main stages, the first stage focused on finding the number of the radiated-elemen that may occupy the outer surface of the reflector which leads to determining the overall size of this particular reflector. In regards to the second stage is where the compensatory reflection phase for the element is calculated. This is done by comparing the calculated phase of the processed plane reflector with the phase of the feed line source. The plane reflector is the one that has the shortest route to the feed line source antenna [11-16]. Phase synthesis platform adopted in this dissertation. Figure 1 shows the key steps of the designing process.

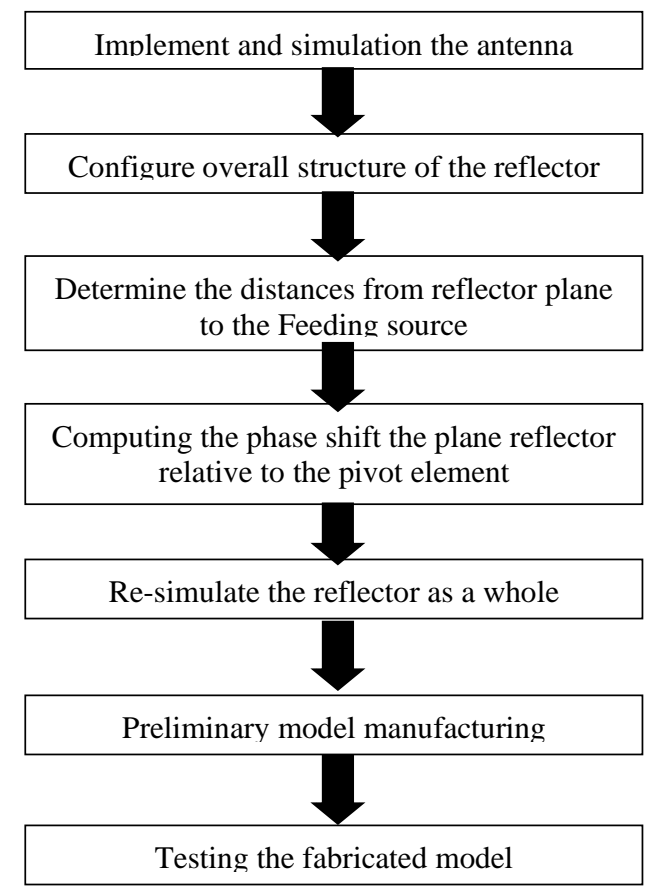

Figure 1. Procedure design of the reflector

The plane of the reflector with the oblique incident wave is being simulated to obtain its dynamic reflection characteristics, the sequence of the method of implementation of the antenna with the reflector of the wave that begins to determine the antenna element and then takes the study of the behavior and type of the reflector and then the composition of the reflector is determined, and then the distance between the level of the reflector and the source of the feed is calculated which takes place in this transport distance. The propagation waves can be calculated from the reflection level which is at a fixed distance with a specific reflection angle. The propagation of the waves can be calculated from the path length by determining the operating frequency. The dimensions of the reflector level are determined by the CST program and the distance between the level of the reflector and the source of the feed is determined using the sweep parameter which gives our best gain antenna.

\section{ANALYSIS OF RADIATION PATTERN OF THE REFLECTOR ANTENNA}

The actual level plane reflector is divided into two regions the first $\mathrm{S} 1$, which fall directly from the source and are illuminated, and the second S2 is shaded and reflected by the reflected and broken rays as a result of the collision of the waves of your source shown in Figure 2. The use of the technique of the actual level plane reflector because it is one of the most important analytical tools for the calculation 
of the field is irregular from the surface reflector and is also a reflective antenna that stimulates the electrons to the passage of electricity that raises the irregular the area on the surface of the conductivity of the space in capacity and the type of polarization known and whenever the surface of the reflector would be more suitable for the induction of a high-wavelength induction current [17-19].

$$
\begin{array}{ll}
J_{s}=2\left(\hat{n} \times H_{\text {inc }}\right) & \text { on } S_{1} \\
J_{S}=0 & \text { on } S_{2}
\end{array}
$$

Where $n^{\wedge}$ is the surface normal and Hinc the incident field. To calculate the irregular field uses a diagonal integration to be inserted expressions [20-25].

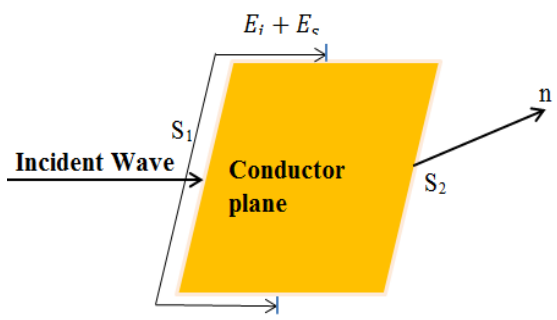

Figure 2. The physical Plane reflector approximation

\section{GEOMETRY ANTENNA PARAMETER}

The parameters geometry proposed antenna are shown in Table 1 and Figure 3(a) and (b) shows the simulation proposed antenna without (a) reflector and (b) manufacturing antenna with a reflector to increase the gain. Figure 4 shows the simulation and manufacturing proposed modified proposed antenna with a reflector.

Table 1. Design proposed parameter antenna

\begin{tabular}{cccccc}
\hline Parameters & Values in $\mathrm{mm}$ & Parameters & Values in $\mathrm{mm}$ & Parameters & Values in mm \\
\hline L & 17 & W & 14 & H & 1.6 \\
Rx & 6 & Ry & 5 & Wf & 2.8 \\
Lf & 5 & XS & 1 & YS & 2 \\
RCS & 2.2 & LG & 4 & WG & 14 \\
Lreflector & 17 & Wreflector & 14 & $\lambda$ & 12 \\
\hline
\end{tabular}

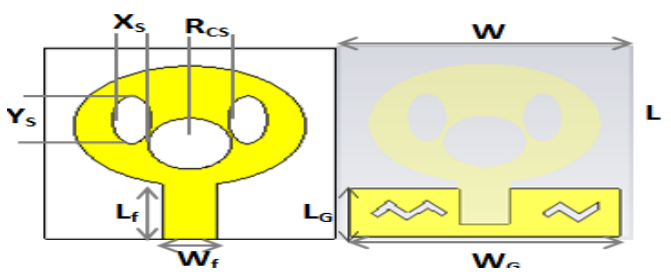

(a)

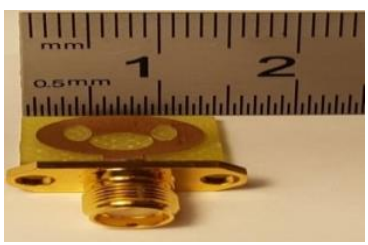

(b)

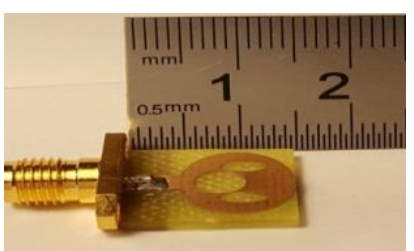

(c)

Figure 3. The antenna proposed without a reflector, (a) Simulation antenna, (b) Manufacture

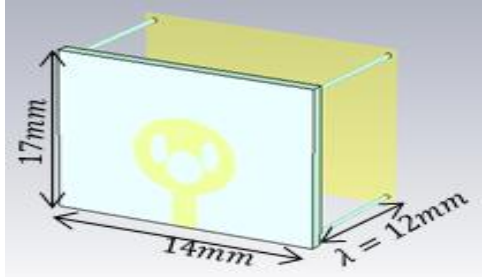

(a)

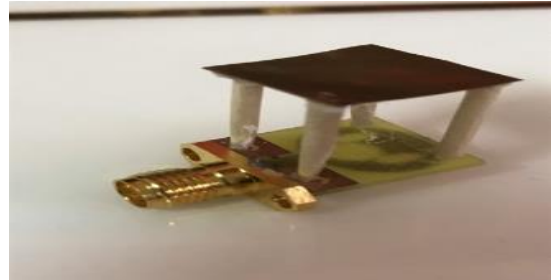

(b)

Figure 4. Design proposed antenna with reflector, (a) Simulation antenna,

(b) Manufacture antenna 


\section{THE RESULT OF REFLECTOR PROPOSED ANTENNA}

Started design and analysis antenna without reflector than the bandwidth of the return reflection coefficient $\mathrm{S} 11$ under $-10 \mathrm{~dB}$ is $24 \mathrm{GHz}$ as the Figure 5(a) and (b) shows (a) simulation result and (b) manufacture result. In order to improve the gain in the proposed antenna, a reflector was used with the antenna and using a sweep parameter for the distance at which the reflector was placed at $(4,812,16) \mathrm{mm}$, we found the best distance is $\lambda$ when the selected $28 \mathrm{GHz}$ bandwidth is $\lambda=12 \mathrm{~mm}$ The gain at a bandwidth at $28 \mathrm{GHz}$ was improved from $(5.48,6.78$, and 7.83$) \mathrm{dB}$ to $11.53 \mathrm{~dB}$, as shown in Figure 6 and Figure 7 shows the compression between the gain with reflector antenna and the gain without a reflector. Figure 8 shown the return reflection coefficient (S11) of the reflector proposed antenna. Figures 9, and 10 shows E-plane distribution at $15.5 \mathrm{GHz}$ and $30 \mathrm{GHz}$, Figures 11 and 12 shows H-plane distribution at $15.5 \mathrm{GHz}$ and $30 \mathrm{GHz}$, Figures 13 and 14 shows surface current distribution at $15.5 \mathrm{GHz}$ and $30 \mathrm{GHz}$, Figure 15, show the gain with far-field broadband distribution at $15.5 \mathrm{GHz}$ and Figures 16 and 17 shows the gain with far field distribution at $15.5 \mathrm{GHz}$ and $30 \mathrm{GHz}$.

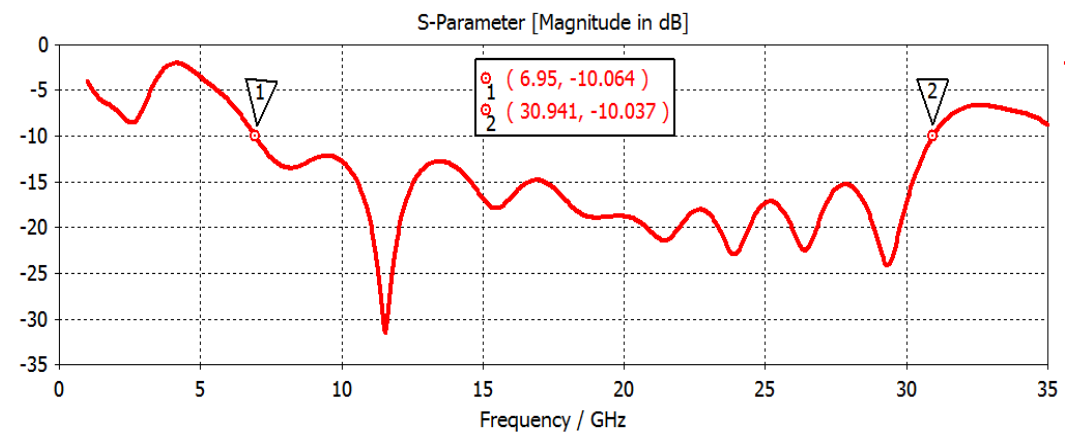

(a)

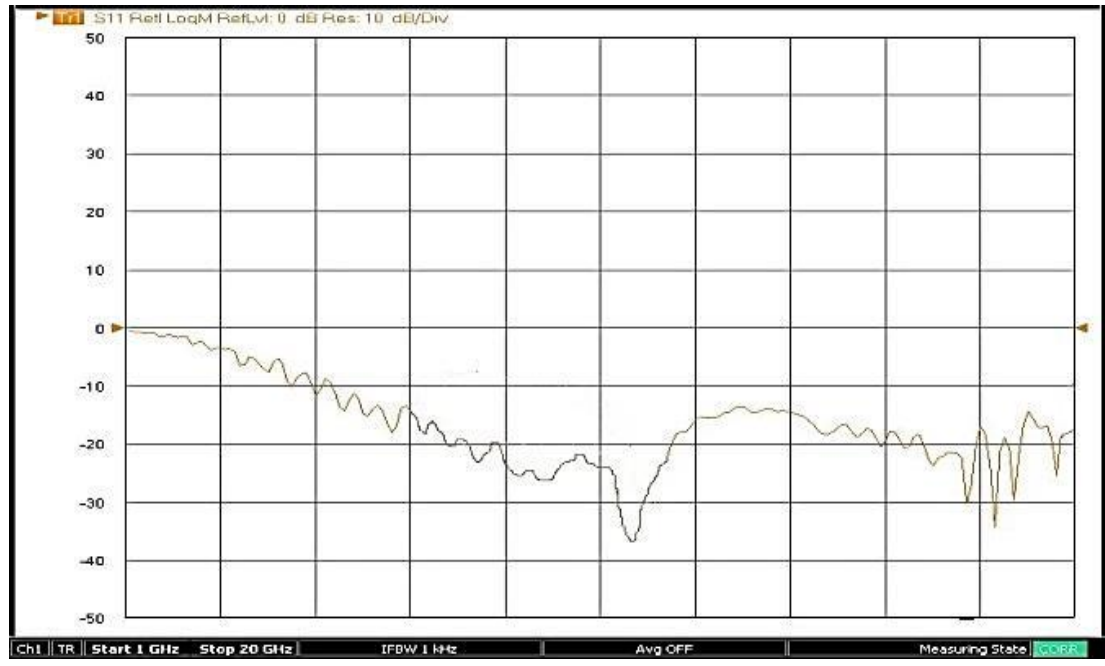

(b)

Figure 5. Reflection coefficient without reflector proposed antenna, (a) Simulation, (b) Manufacture

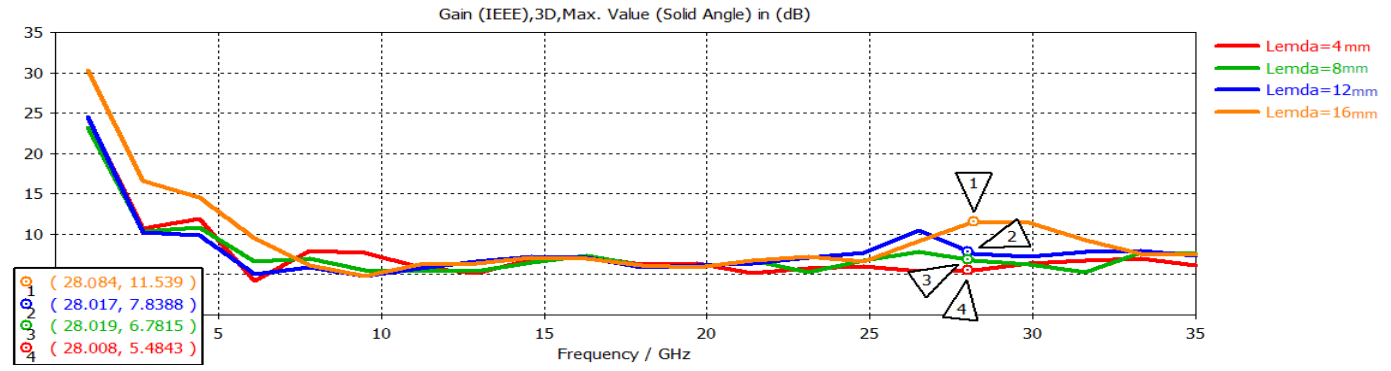

Figure 6. Gain with a different distance of reflector proposed antenna 


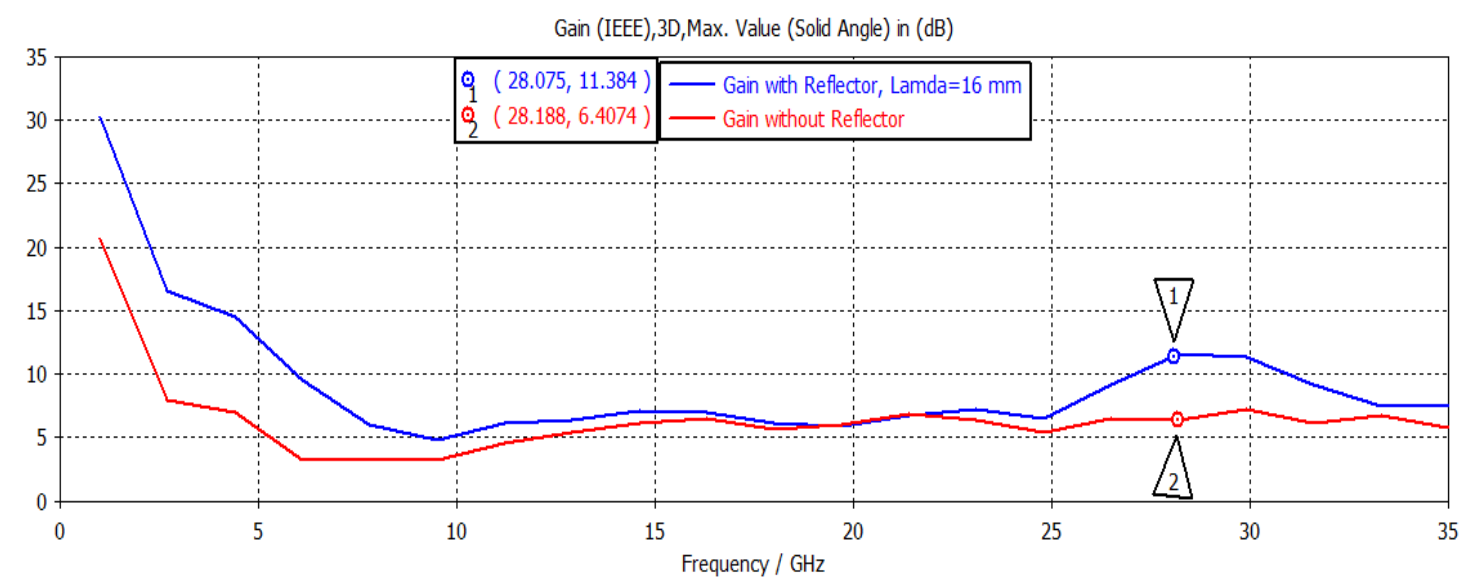

Figure 7. The gain of with reflector and without of proposed antenna

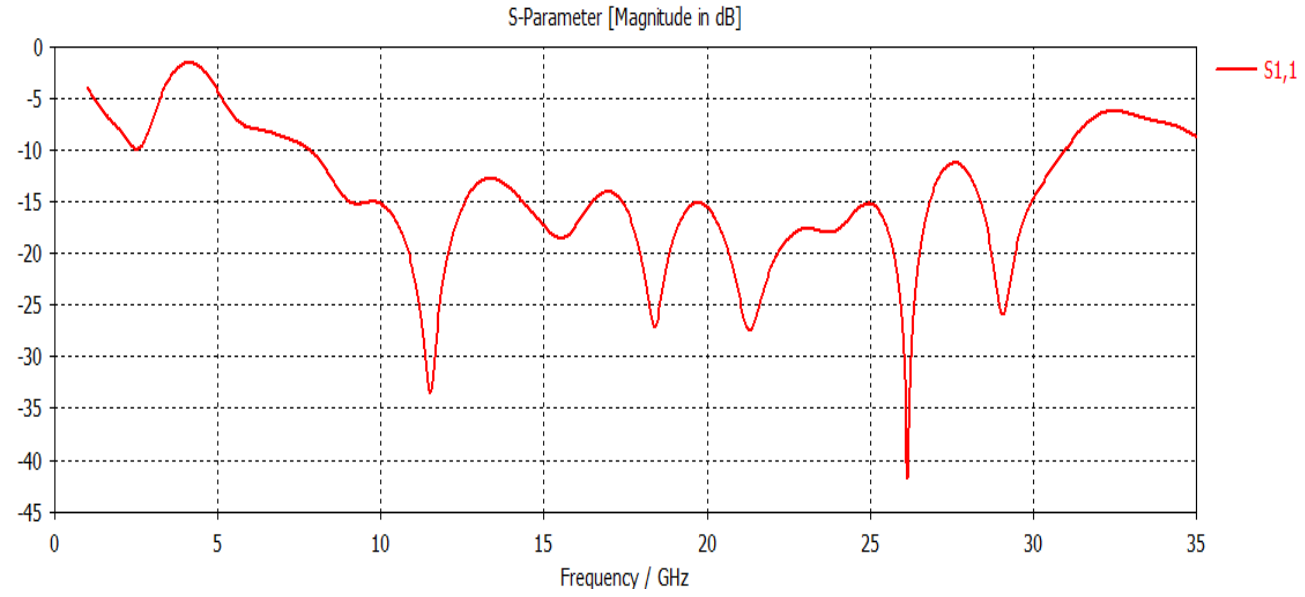

(a)

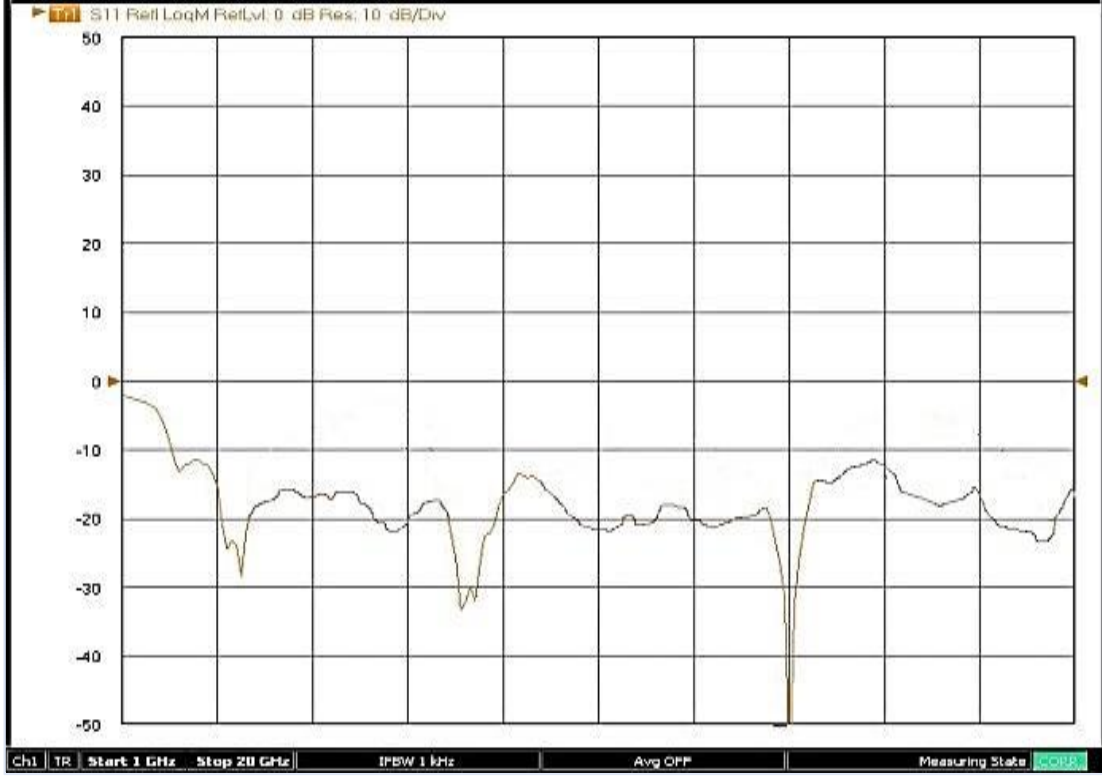

(b)

Figure 8. The reflection coefficient of the reflector proposed antenna, (a) Simulation, (b) Manufacture 


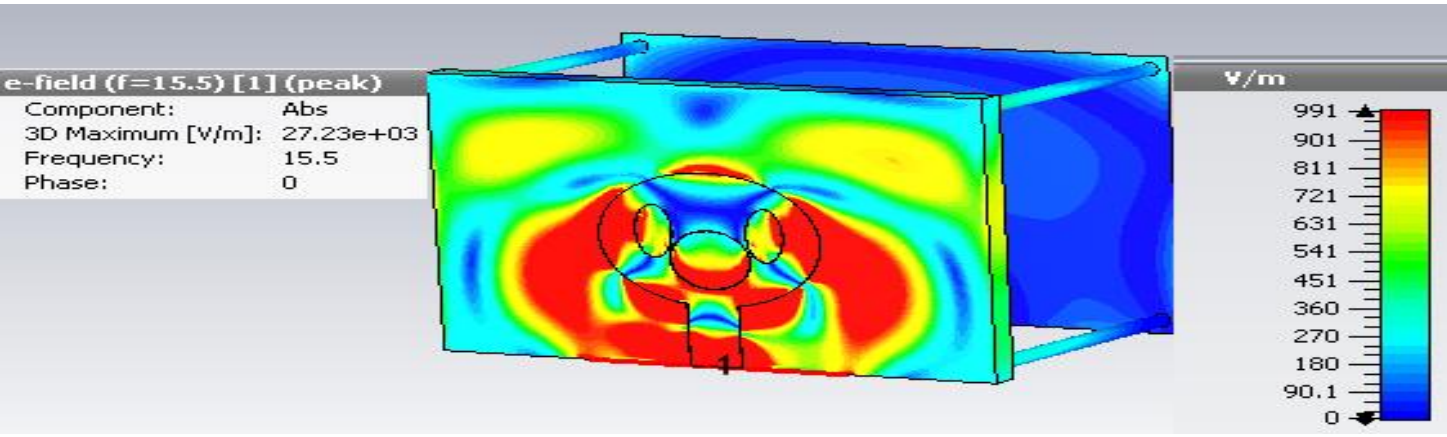

Figure 9. E-filed distribution at $15.5 \mathrm{GHz}$

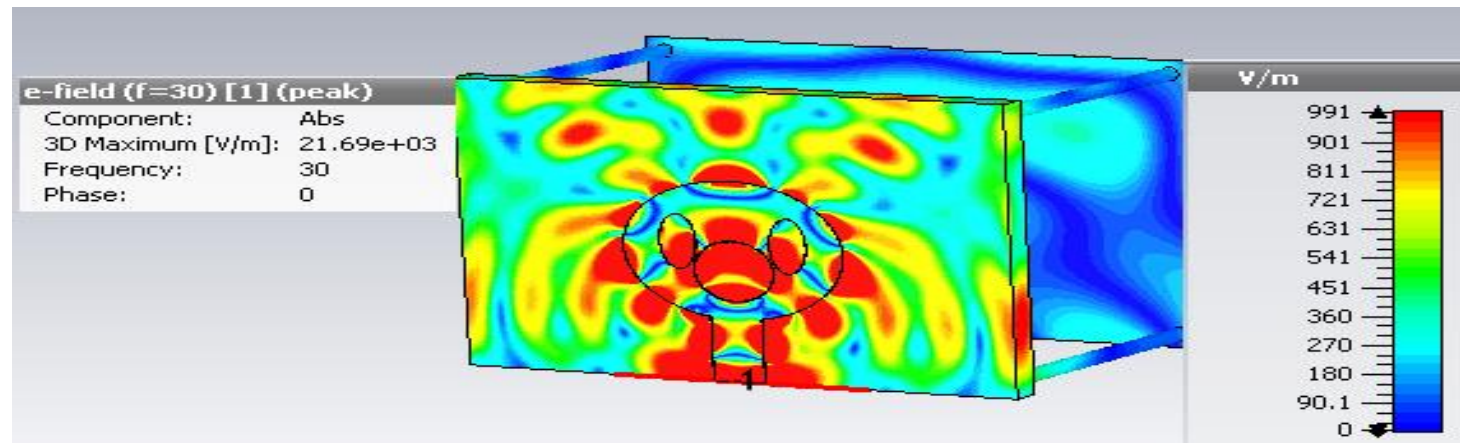

Figure 10. E-filed distribution at $30 \mathrm{GHz}$

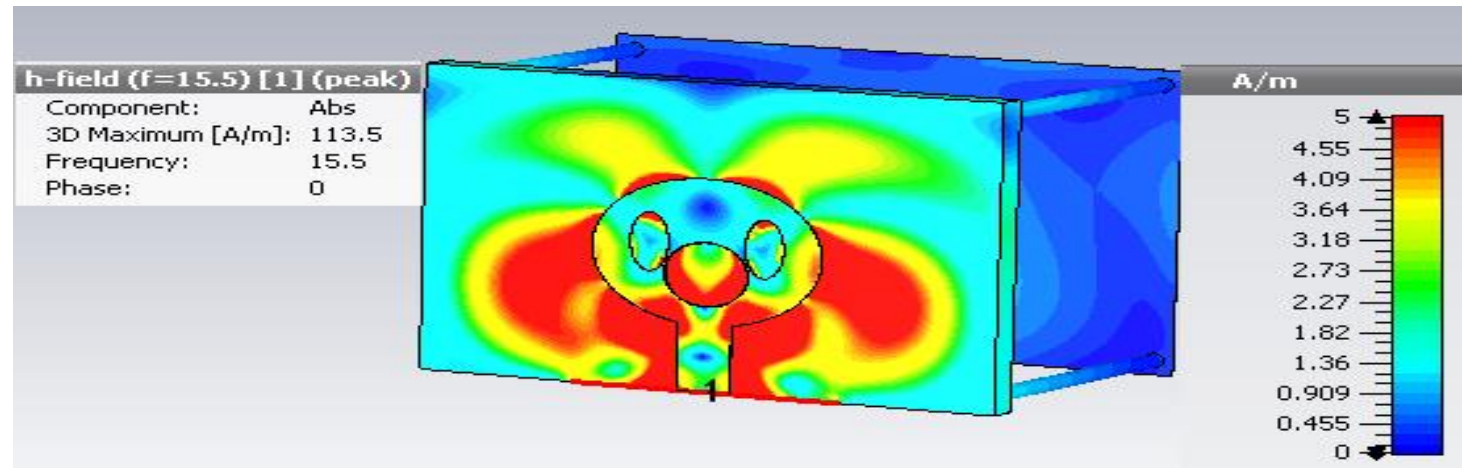

Figure 11. H-filed distribution at $15.5 \mathrm{GHz}$

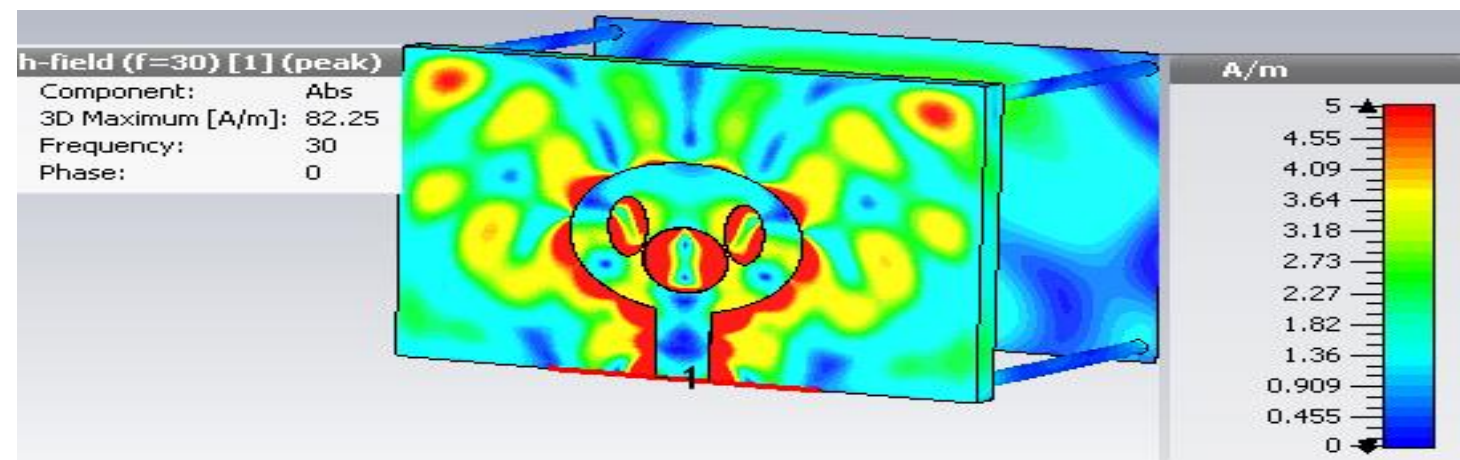

Figure 12. H-filed distribution at $30 \mathrm{GHz}$ 


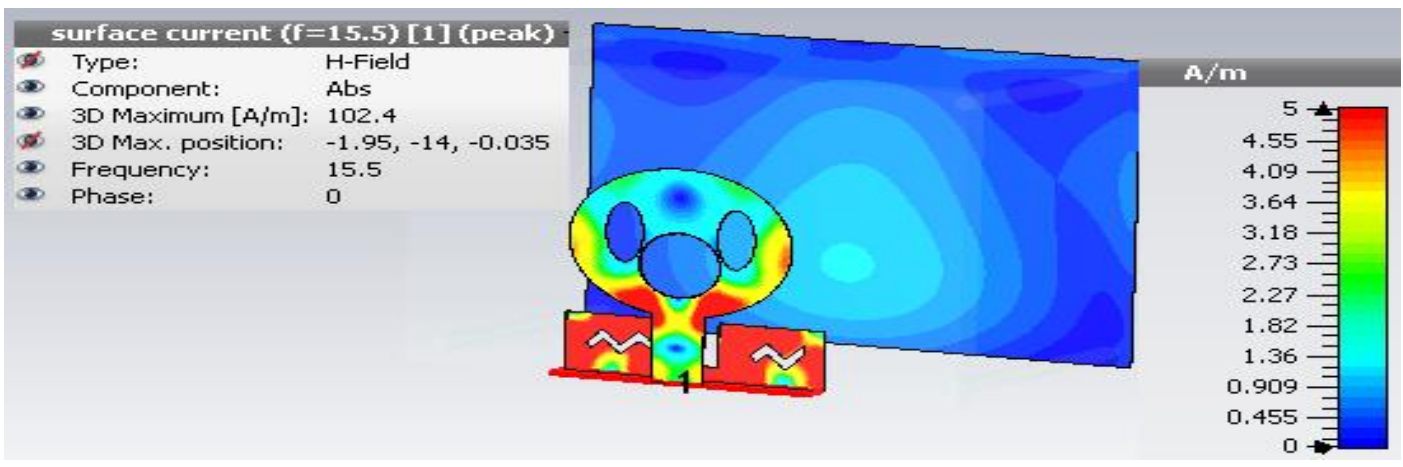

Figure 13. Surface current distribution at $15.5 \mathrm{GHz}$

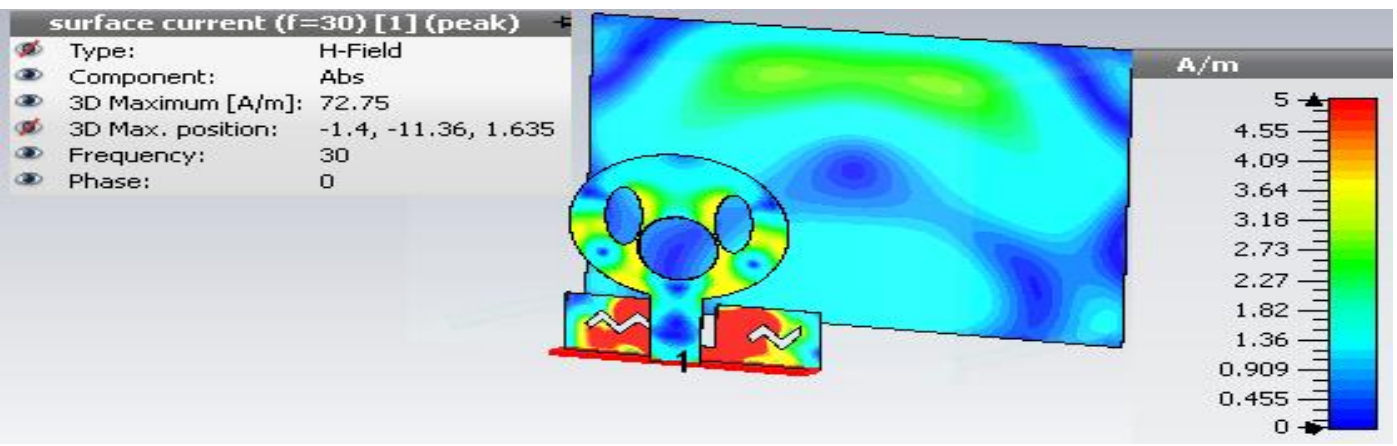

Figure 14. Surface current distribution at $30 \mathrm{GHz}$

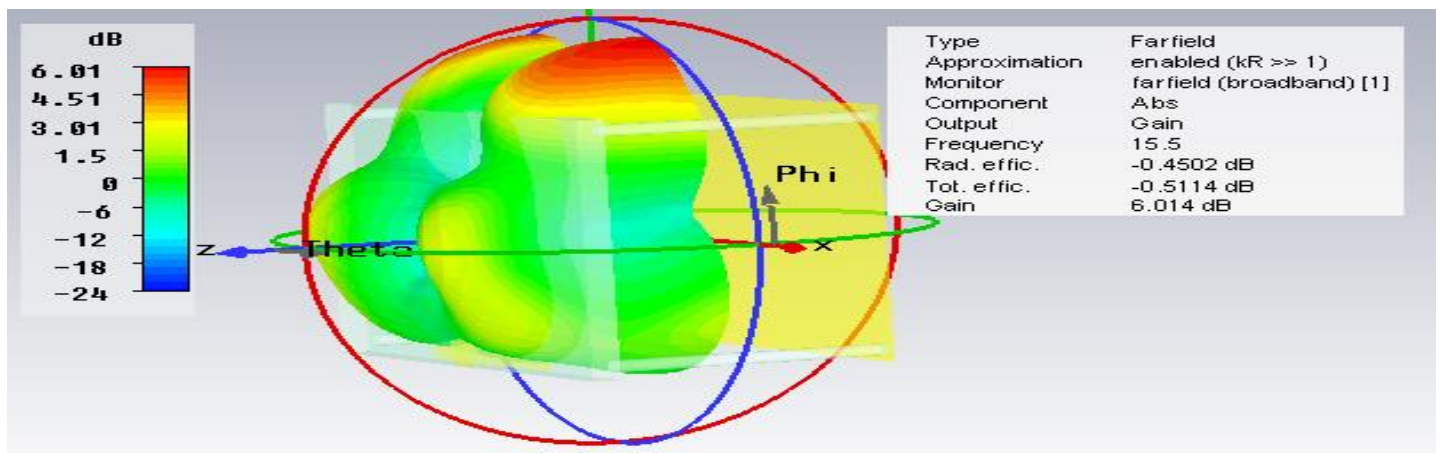

Figure 15. Gain with far-field broadband distribution at $15.5 \mathrm{GHz}$

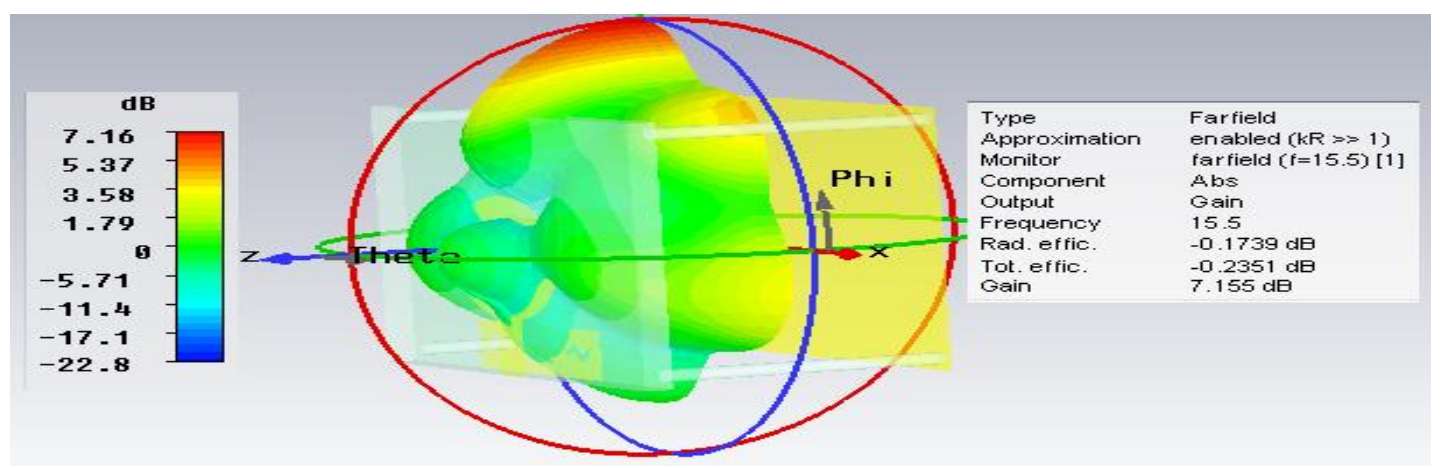

Figure 16. Gain with far field distribution at $15.5 \mathrm{GHz}$ 




Figure 17. Gain with far field distribution at $30 \mathrm{GHz}$

\section{CONCLUSION}

Design and analysis of antenna parameter requirement to improve the gain of the proposed antenna have been used reflector behind the ground. The best sit was selected for the opposite so that we get higher gains by used sweep parameter, at which the reflector was placed at $(4,8,12,16)$ then the best distance is $\lambda$ where $\lambda$ equal $12 \mathrm{~mm}$, when selected the bandwidth is $28 \mathrm{GHz}$. The antenna gain with reflector a at the bandwidth $28 \mathrm{GHz}$ was improved from $(5.48,6.78$, and 7.83$) \mathrm{dB}$ to $11.53 \mathrm{~dB}$ while the antenna gain without reflector in the same bandwidth is $6.8 \mathrm{~dB}$.

\section{ACKNOWLEDGMENTS}

The authors would like to thank Mustansiriyah university (www.uomustansiriyah.edu.iq) Baghdad-Iraq for its support in the present work. The authors would like to give special thanks to the anonymous referee for suggesting several pertinent issues which have enabled us to improve the manuscript substantially.

\section{REFERENCES}

[1] D. Berry, R. Malech and W. Kennedy, "The reflectarray antenna," in IEEE Transactions on Antennas and Propagation, vol. 11, no. 6, pp. 645-651, November 1963.

[2] H. R. Phelan, "Spiral phase reflectarray for multi-target radar," Microwave Journal, vol. 20, pp. 67-73, 1977.

[3] C. S. Malagisi, "Microstrip disc element reflectarray," Electronics and Aerospace Systems Convention, pp. 186-192, 1978.

[4] D. M. Pozar, and T. A. Metzler, "Analysis of a reflectarray antenna using microstrip patches of variable size," Electronics Letters, vol. 29, no. 8, pp.657, 1993.

[5] M. Arrebola, J. A. Encinar, L. F. de la Fuente and G. Toso, "Contoured-beam reflectarray for DBS application including copolar isolation requirements between missions," 2009 3rd European Conference on Antennas and Propagation, Berlin, 2009, pp. 844-848.

[6] Ali Khalid Jassim, and Raad H. Thaher, "Calculate the optimum slot area of elliptical microstrip antenna for mobile application," Indonesian Journal of Electrical Engineering and Computer Science, vol. 16, no. 3, pp. 1364-1370, 2019.

[7] J. A. Encinar, M. Arrebola, L. F. de la Fuente and G. Toso, "A transmit-receive reflectarray antenna for direct broadcast satellite applications," in IEEE Transactions on Antennas and Propagation, vol. 59, no. 9, pp. 3255-3264, Sept. 2011.

[8] Capozzoli, Amedeo, et al. "Phase-only synthesis of flat aperiodic reflectarrays," Progress in Electromagnetics Research, 133, pp. 53-89, 2013.

[9] Min Zhou, et al., "Investigations on accurate analysis of microstrip reflectarrays," In 33rd ESA Antenna Workshop on Challenges for Space Antenna Systems, 2011.

[10] E. Girard, R. Moulinet, R. Gillard and H. Legay, "An FDTD optimization of a circularly polarized reflectarray unit cell," IEEE Antennas and Propagation Society International Symposium (IEEE Cat. No.02CH37313), San Antonio, TX, USA, 2002, pp. 136-139.

[11] F. -. E. Tsai and M. E. Bialkowski, "Designing a 161-element Ku-band microstrip reflectarray of variable size patches using an equivalent unit cell waveguide approach," in IEEE Transactions on Antennas and Propagation, vol. 51, no. 10, pp. 2953-2962, Oct. 2003.

[12] Ali Khalid Jassim, and Raad H. Thaher, "Enhancement gain of broadband elliptical microstrip patch array antenna with mutual coupling for wireless communication," Indonesian Journal of Electrical Engineering and Computer Science vol. 13, no. 1, March, pp. 401-408, 2019. 
[13] M. A. Milon, R. Gillard, D. Cadoret, and H. Legay, "Comparison between the infinite-array approach and the surrounded-element approach for the simulation of reflectarray antennas," IEEE AP-S/URSI Symposium, Albuquerque, New Mexico, 2006.

[14] J. Huang and R. J. Pogorzelski, "A Ka-band microstrip reflectarray with elements having variable rotation angles," in IEEE Transactions on Antennas and Propagation, vol. 46, no. 5, pp. 650-656, May 1998.

[15] J. Huang," Bandwidth study of microstrip reflectarray and a novel phased reflectarray concept," in Antennas and Propagation Society Intl. Symp. AP - S. Digest, pp. 582-585, 1995.

[16] J. Shaker, M. R. Chaharmir, M. Cuhaci and A. Ittipiboon, "Reflectarray research at the communications research centre Canada," in IEEE Antennas and Propagation Magazine, vol. 50, no. 4, pp. 31-52, Aug. 2008.

[17] Ali Khalid Jassim, and Raad H. Thaher, "Design and analysis of broadband elliptical microstrip patch antenna for wireless communication," TELKOMNIKA Telecommunication Computing Electronic and Control, vol. 16, no. 6, pp. 2493-2500, December 2018.

[18] G. Veal and M. Thomas, "Highly accurate inflatable reflectors," Final Report, AFRPL Report TR84-021, Air Force Rocket Propulsion Laboratory (renamed Air Force Astronautics Laboratory), 1984.

[19] R. E. Freeland, G. D. Bilyeu, and G. R. Veal, "Large inflatable deployable antenna flight experiment results," IAF paper 97-1.3.01,48th Congress of the International Astronautical Federation (Turin, Italy), International Astronautical Federation, Paris, France, October, 1997.

[20] J. Huang, "Emerging array antenna technologies at JPL," Antenna Technology and Applied Electromagnetics (ANTEM) Symposium, Ottawa, Canada, August, 1998

[21] Ali Khalid Jassim, and Raad H. Thaher, "Design of MIMO (4x4) broadband antenna array for mm-wave wireless communication applications," International Journal on Engineering Applications (IREA), vol. 07, no. 2, 2009.

[22] A. S. A. Pingale, A. Jadhav, C. Ghanote, and U. Sonare, "Design of elliptical microstrip antenna for ultra wide band applications," International Journal of Engineering and Technical Research (IJETR), vol. 3, no. 3, pp. 276-279, 2015.

[23] J. Iqbal, U. Illahi, M. I. Sulaiman, M. Alam, M. S. Mazliham, and L. S. Ding, "Mutual coupling reduction in circularly polarized dielectric resonator MIMO antenna," Indonesian Journal of Electrical Engineering and Computer Science, vol. 15, no. 1, pp. 266-273, July 2019.

[24] Siti Rohani Tajuddin, S. N. Azemi, P. J. Soh, C. B. M. Rashidi, and A Abdullah Al-Hadi, "Analysis and design of directive antenna using frequency selective surface superstrate," Indonesian Journal of Electrical Engineering and Computer Science, vol. 14, no. 2, pp. 529-536, May 2019.

[25] A. S. Abdullah and M. J. Farhan, "A novel two open terminals slot antenna for ultra wideband wireless communication applications," 2018 1st International Scientific Conference of Engineering Sciences-3rd Scientific Conference of Engineering Science (ISCES), Diyala, 2018, pp. 108-113. 